\title{
60 YEARS OF NEUROENDOCRINOLOGY MEMOIR: Geoffrey Harris and my brush with his unit
}

\section{Geoffrey Raisman}

Spinal Repair Unit, Department of Brain Repair and Rehabilitation, UCL Institute of Neurology, Queen Square, London WC1N 3BG, UK

Correspondence should be addressed to G Raisman Email G.Raisman@ucl.ac.uk

\begin{abstract}
Geoffrey Harris is chiefly known for his demonstration of the control of the pituitary gland by the portal vessels coming from the hypothalamus. This does not do justice to his extraordinary contribution to biology. Harris' life's work was central in demonstrating the brain/body interactions by which animals and humans adapt to their environment, and above all the control of that most crucial and proximate of all evolutionary events reproduction. In this brief review, I have tried to put Geoffrey Harris' work in the context of the scientific thinking at the time when he began his work, and above all, the contribution of his mentor, FHA Marshall, on whose towering shoulders Harris rose. But this is mainly my personal story, in which I have tried to show the debt that my work owed to Harris and especially to my dear friend, the late Keith Brown-Grant in Harris' team. I myself was never an endocrinologist, but over a short period in the early 1970s, under the influence of such inspirational mentors, and using purely anatomical methods, I was able to demonstrate sexual dimorphism and hormone-dependent sexual differentiation in the connections of the preoptic area, regeneration of the median eminence, the ultrastructure of apoptosis, the requirement for the suprachiasmatic nuclei in reproductive rhythms, the existence of non-rod or cone photoreceptors in the albino rat retina and, later, the expression of vasopressin by solitary (one in 600) magnocellular neurons in the polydipsic di/di Brattleboro mutant rat; this phenomenon was subsequently shown to be due to $a+1$ reading frameshift. I end this brief overview by mentioning some of the abiding and fascinating mysteries of the endocrine memory of the brain that arise from Harris' work on the control of the endocrines, and by pointing out how the current interest in chronobiology emphasises what a Cinderella the endocrine mechanisms have become in current brain imaging studies.
\end{abstract}

\section{Key Words}

$\checkmark$ endocrine memory

- sexual differentiation

- circadian rhythm

- diabetes insipidus

\section{Introduction}

Before Geoffrey Harris, most people would have regarded the production of eggs as a matter for the pelvis, the production of urine as a matter for the kidney and the difference between males and females as a matter for $\mathrm{X}$ and $\mathrm{Y}$ chromosomes. As for the endocrine system, it was presented as a self-contained compartment of physiology, governed by the pituitary gland, which had been described in the words of Sir Walter Langdon-Brown, in 1931, as the 'leader of the endocrine orchestra' (Hubble 1961).

This paper is part of a thematic review section on 60 years of neuroendocrinology. The Guest Editors for this section were Ashley Grossman and Clive Coen. 
Of course, the tidiness of this physiological complacency had been questioned, most impressively by Francis (FHA) Marshall, who was Harris' mentor in Cambridge (Harris 1972), and who was undoubtedly the most important formative influence on Harris' scientific life. What interested Marshall was the link between the environment and the endocrine system. Animals in the wild mate at the most suitable time of the year for raising young. 'Generative activity in animals,' wrote Marshall, 'occurs only as a result of definite stimuli, which are partly external...' (Marshall 1922).

It seemed that a significant link to the environment must depend on sensory, i.e. 'exteroceptive' inputs to the brain, and one of Harris' first observations was to show that ovulation could be induced by electrical stimulation of the brain (Harris 1937). But the mechanism by which the brain could control the endocrine system was still mysterious.

Around the same time, Berta Scharrer in Frankfurt had proposed the concept of 'gland nerve cells' in invertebrates (Scharrer 1936), later known as neurosecretion. Subsequently, it was shown that, in vertebrates, the large 'magnocellular' neurons of the hypothalamic supraoptic and paraventricular nuclei synthesise the nonapeptides vasopressin (antidiuretic hormone) and oxytocin. These molecules are carried down their axons to be released into the capillary circulation of the posterior pituitary gland (e.g. Douglas \& Poisner 1964, Bargmann 1966). From there, they enter the general circulation to reach their distant target organs - the kidney and the reproductive smooth muscle.

The majority of cells in the mediobasal hypothalamus are smaller - the so-called 'parvicellular' neurons. They form a cluster around the base of the third ventricle called the 'arcuate' nucleus and send their axons a short distance to the ventral surface of the brain, where they terminate on a specialised bed of fenestrated capillaries called the median eminence (Cajal 1911).

Harris demonstrated that the capillary blood from the median eminence does not enter the general circulation, but drains into a series of veins that travel down the pituitary stalk and then break up into a second capillary network in the anterior pituitary gland. Harris postulated that this portal system provides a route through which shorter range hormones, secreted by the parvicellular hypothalamic neurons, are targeted locally to the anterior pituitary, where they stimulate the secretion of anterior pituitary hormones into the systemic circulation. He proposed that the hypothalamo-hypophysial portal vascular system constitutes the link that allows the brain to control the release of secretions by the anterior pituitary gland into the general circulation (Vogt 1972, Raisman 1997).

These short-range neurosecretions were called 'releasing factors', and Harris proposed that each specific class of parvicellular hypothalamic neurons synthesised a unique releasing factor, probably one of a series of polypeptides of the same family as the nonapeptides of the magnocellular system, and selectively targeted to each of the specific classes of pituitary cells producing the different anterior pituitary hormones. According to this view, ovulation is governed by gonadotrophin-releasing factors that are produced by a specific class of parvicellular hypothalamic neurons and which travel via the hypothalamo-hypophysial portal system to stimulate the release of anterior pituitary gonadotrophins into the general circulation through which they control ovulation and the secretion of sex steroids by the ovary.

Behind Harris' desk in Oxford there hung a small black-and-white photograph of a rather severe looking nineteenth century dignitary. Harris loved to puzzle his visitors by asking them who they thought this was. It was Claude Bernard, the originator of the concept of the constancy of the milieu interieur- homoeostasis. Harris was going to take this idea a step forward - how the brainendocrine link enabled the level of homoeostasis to be adapted to the events in the environment. In the words of Yasumasa Arai, 'Harris put the brain into the endocrine system,' and for the rest of his life Harris would investigate the links in the chain of events that led from environmental influences through the brain to the control of the endocrine system (Vogt 1972, Raisman 1997). And, as anticipated by Marshall, it was the influence of light on reproduction that would be a royal route of investigation.

\section{Sexual dimorphism in the brain}

I encountered Harris' team by chance in 1962 when he succeeded Sir Wilfred LeGros Clark as Professor of Anatomy in Oxford. Harris was already a celebrity. There was an unmissable aura about Harris as he strode with quiet confidence along the corridors, or stood in a gathering. For a young new graduate, the experience of coming face to face with the eminent new Head of Department, with his solid frame and bullet head, was an awe-inspiring event. What I did not realise until much later, and only on looking back, was his deep, wellconcealed kindliness (Fig. 1). I was seeking an independent existence as a neuroanatomist, and one of Harris' first acts was to adopt me. He gave me my first, one-room laboratory.

Published by Bioscientifica Ltd 


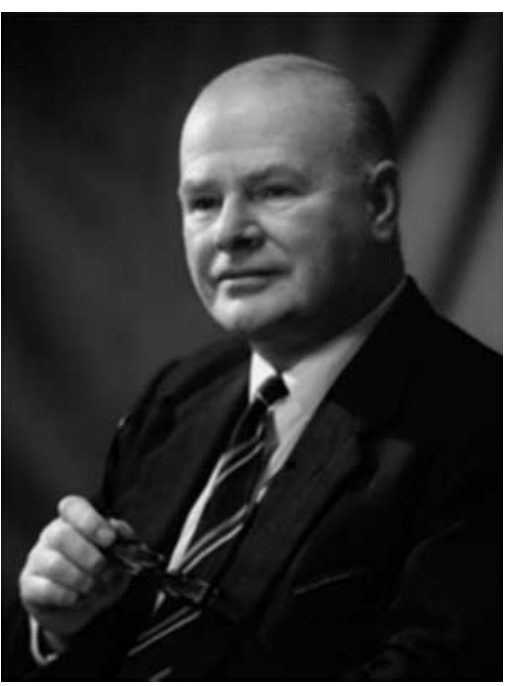

Figure 1

Geoffrey Wingfield Harris (Bassano Ltd, National Portrait Gallery, UK NPG X172149). Reproduced with permission.

Harris did not attempt to influence the topic of my research, but he changed the course of my life by another type of reconstruction, when he had the cellars of the Department of Human Anatomy excavated to create a semi-subterranean canteen. High up in the walls, small windows opening close to ground level outside allowed weak daylight and the footsteps and clip-clopping of the ankles of passers by outside to percolate into the cavernous room. It was there that I found a bridge playing partner in Keith Brown-Grant in Harris' MRC Unit. And it was there I first became acquainted with the endocrine concept of timing - the so-called 'critical periods'. The impossible two no-trump bids which Keith made on the last hand as he rose at $1400 \mathrm{~h}$ we dubbed the two no-trump releasing factor.'

Before I left Oxford 10 years later, at least three major projects had stemmed from these influences on me. And I was left with the puzzle of endocrine memory that to this day I find absolutely fascinating. But let's not jump to the end.

The laboratory rat has a 4-5-day ovulatory cycle (Everett \& Sawyer 1950). Under normal circumstances, ovulation is regulated by a feedback system from the ovary. To eliminate this variable, rats were gonadectomised and a model feedback system was created. The ovarian input was imitated by giving 4 days of oestrogen priming followed by a single dose of progesterone. As in the intact female rat, this elicits a surge of gonadotrophin from the pituitary. The ovariectomised oestrogen-primed rat became the work horse of Harris' team.
In contrast, in the castrated male rat, oestrogen priming and progesterone produce no such surge. Moreover, by transplanting pituitaries of males into females and those of females into males, Harris demonstrated that this difference between the sexes lies not in the pituitary gland but in the brain (Harris \& Campbell 1966). Evidence from stimulation, recording, and the effect of lesions had revealed that the preoptic area, a small region at the anterior end of the hypothalamus, was involved in, and crucial for generating the ovulatory surge of gonadotrophins (Everett et al. 1949, Koves \& Halasz 1970).

I had just come from developing a quantitative electron microscopic technique for studying the formation of new synapses in the adult brain after injury (Raisman 1969a). Now, with Keith Brown-Grant, I planned to use this new technical approach to see whether examination of the synaptic arrangements in the rat preoptic area could reveal a structural difference between male and female rats.

The question was where to look? The preoptic area may be a small speck in the light microscope. But going up to the millions-fold magnification needed to see synapses, it was like trying to find which pebbles to count in the Gobi Desert. I needed a divining rod.

It had been shown that stimulation of the amygdaloid nuclei could induce ovulation in the rat. The amygdala sends fibres through a tract called the stria terminalis to a wide array of brain areas; among them is the preoptic area. Transection of the stria terminalis prevents the ovulatory response to stimulation of the amygdala (Velasco \& Taleisnik 1969). So I used the stria terminalis as the guide to lead me to the ovulatory centre in the preoptic area.

In my previous study, I had used the fact that 2 days after cutting a fibre tract the synaptic terminals of the severed fibres became electron dense, and were thus readily detected using the electron microscope (Raisman 1969b). So now I could use the presence of electron-dense synapses to locate the part of the preoptic area receiving amygdaloid projections. This housed the presumptive ovulation-inducing mechanism that was present in female brains and absent in males. Could I show there was a structural difference?

Using an electron microscope, I classified the synapses according to their mode of termination and counted them. Approximately $88 \%$ were on dendritic shafts, $7 \%$ on dendritic spines and $4-5 \%$ on cell somata. Two days after transection of the stria terminalis, the electron-dense degenerating terminals of the amygdaloid projection fibres accounted for approximately half of the synapses on dendritic spines (Fig. 2).

Published by Bioscientifica Ltd 
Now I compared males and females. In the area receiving amygdaloid projections, one category of spine synapses was twice as common in females as males. This category was the non-amygdaloid synapses on dendritic spines. The incidences of all the rest were indistinguishable between the sexes (Raisman \& Field 1971).

The fact that the incidences of the other classes of synapses were the same between the sexes provided a control. It meant that the sexual dimorphism was not due to differences in overall size or density of the neuropil. And the sexually dimorphic features were not the amygdaloid projections themselves, as they were the same in both sexes. The difference was in the target area to which the amygdala projects. The amygdala was sending fibres to a sexually dimorphic area.
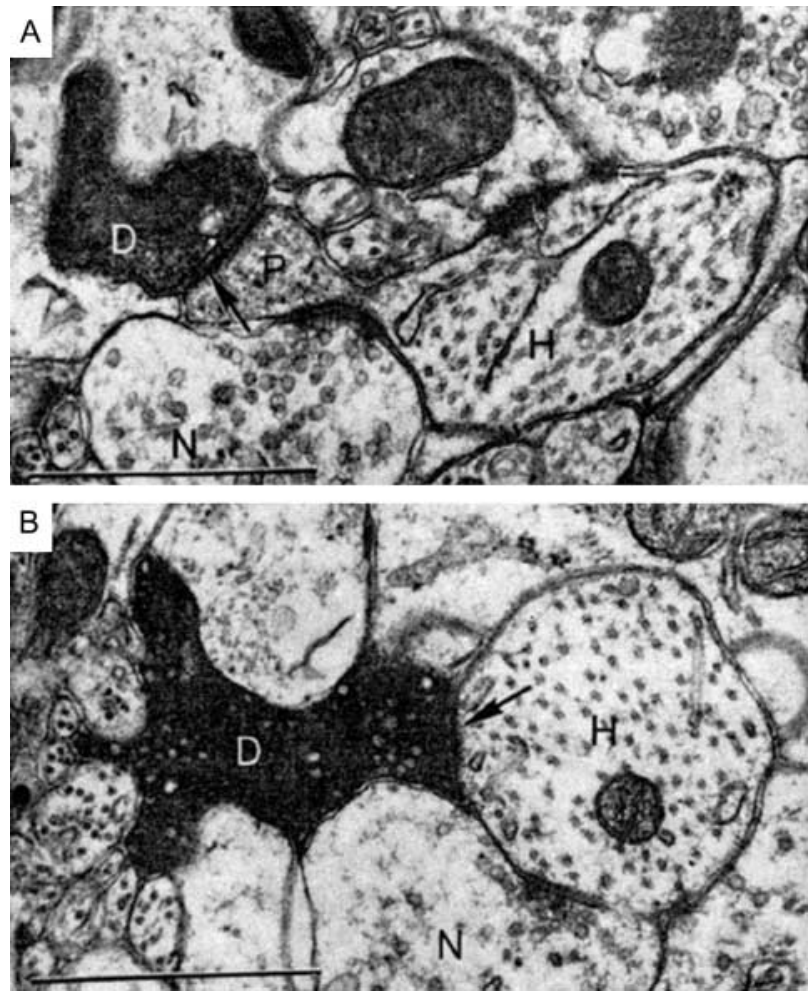

Figure 2

Axon terminals (D) in the preoptic area, showing collapse and increased electron opacity associated with orthograde degeneration 2 days after a lesion of the stria terminalis. Adjacent, non-degenerating terminals (N). In $(A)$ the degenerating terminal makes synaptic contact with a dendritic spine $(P)$, which is connected by a narrow neck to a dendritic shaft $(H)$, a configuration commoner in the female. In (B), the contact that is directly on to a dendritic shaft $(H)$ is of the type commoner in the male. Arrows mark synaptic thickenings. Dendritic shafts are identified by their content of microtubules cut in transverse or oblique section. Scale bars, $1 \mu \mathrm{m}$. Reproduced, with permission, from Raisman G \& Field PM 1971 Sexual dimorphism in the preoptic area of the rat. Science 173 731-733. Copyright 1971 The American Association for the Advancement of Science.
As spine synapses are generally excitatory, it would be tempting to speculate that the higher number of spine synapses in the female preoptic area is associated with an increased level of excitability in the female preoptic area. But until the anatomical origin of the dimorphic class of synapses is identified, this remains only a thought (Clarkson et al. 2014).

The identification of a sexually dimorphic pattern of synapses in a part of the brain specifically implicated in induction of ovulation was welcome to Geoffrey Harris. Elsewhere, the idea that male and female brains were different had a more uncertain reception. This came at period when the women's liberation movement was at one of its demonstrative peaks. In the USA, this was a time when a man politely opening a door for a lady risked getting it slammed in his face. I was invited by Simone Veil, the French Minister of Health to present my findings at a conference on the topic 'The Fact of Femininity' in Paris (Raisman 1978). Fortunately, my electron microscopic evidence that the male and female rat brains were structurally different was too obscure for me to experience any difficult decisions at doorways.

\section{Sex determination}

My own interest in synapses originated from my finding of new synapse formation after injury, which I had called 'plasticity' (Raisman 1969a). The idea that the adult brain can respond to injury by forming new connections had been received with considerable scepticism by both the scientific and the medical communities. I was always on the look-out for new areas where I might obtain evidence to support the idea of plasticity of synaptic connections. So I was fascinated to learn of Harris' interest in the mechanism of determination of sex (Harris \& Campbell 1966).

Here again, Harris was following Marshall:

'If it be true,' Marshall wrote, 'that all individuals are potentially bisexual ... it would seem extremely probable that the dominance of one set of sexual characters over the other may be determined ... at an early stage of development in response to a stimulus which may be either internal or external ... Castration, or the introduction of another gonad ... may initiate changes in the direction of the opposite sex, or even bring about a complete sex-reversal.' (Marshall 1922, Pfeiffer 1936).

By the time of Harris' review (Harris \& Campbell 1966), it had been shown that both the presence of an ovulatory inducing mechanism and the development of sex-specific behaviour patterns in the rat brain are not determined by the genetic sex of the rat (XX or XY) but by the production

Published by Bioscientifica Ltd 
of circulating sex steroids by the developing gonad during a critical perinatal period. The same differentiating effects are also present in human sexual development (Money et al. 1968, Money \& Ehrhardt 1971).

During late embryonic life, and for roughly the first 7-10 days after birth, the rat testis is actively secreting steroids. The ovary is not yet secreting steroids. If the testes are removed at birth from a newborn male rat, its brain will develop an adult female-type ovulatory mechanism and a female lordotic type of behavioural response to a male. Harris demonstrated that an ovary transplanted into adult males that had been castrated at birth would show cyclic ovulation. This meant that the anlage of the female ovulatory mechanism is present in the male brain at birth, but is prevented from developing in intact males by the exposure of the neonatal brain to androgens secreted by the male gonad.

Since the neonatal female gonad does not secrete sex steroids as yet, the brain is not exposed to them, and the ovulatory mechanism in the brain is preserved. But if the male pattern of early exposure to androgens is imitated by injecting single dose of androgen into a female rat during the critical neonatal period, the ovulatory mechanism fails to develop, and the resulting adult female is permanently sterile.

This provided me with a way to look at plasticity in development. I asked Harris to show me the forbiddingly delicate microsurgery of tiny neonatal rats. He came up to my office, bringing a stained and well-used open cardboard box in which gleamed the tiny glass hooks he had fashioned himself over the years for the precise anatomical approaches of the operations. He worked through a dissecting microscope on my desk, with his lit cigarette end perched over the desk edge. I marvelled at his rock steady hands. He demonstrated and explained patiently, then stood up leaning over my chair back while he checked I could repeat the delicate procedures. Then he strode to the door.

'Your instruments,' I said, indicating the cardboard treasure box.

Harris stopped with his hand on the handle of the half-open door, gave me a withering backward glance and left without a word, closing the door behind him. I had been unwittingly ungracious - I did not understand that he was passing on his legacy. By now, he was a sick man, in his last year. I never met with him again. But with that help I now produced six categories of rat:

i) normal adult males;

ii) normal adult females; iii) adult males that had been castrated within $12 \mathrm{~h}$ of birth;

iv) a control group of adult males that had been castrated at 14 days of life (after the critical period);

v) adult females that had been administered androgen on the fourth day of life (during the critical period); and

vi) a control group of adult females that had been administered with androgen on the 16th day (after the critical period).

After they had become adults, Keith tested each of the six groups of rats for their ability to generate an ovulatory surge of hormones and to exhibit female-type receptive behaviour (lordosis) in response to males. As before, using the amygdaloid projection as a key, I counted synapses in the sexually dimorphic part of the preoptic area. The six groups were counted blind.

When the data were decoded, it confirmed that, as before, non-amygdaloid spine synapses in the preoptic area were twice as numerous in the normal female group as in the normal males.

In both the group of neonatally castrated males and the group of females treated with steroid on the 16th postnatal day (after the critical period), Keith showed functionally that, after gonadectomy followed by oestrogen priming and progesterone, both groups of adults were capable of generating a surge of pituitary gonadotrophins and lordosed in response to advances by male rats. This indicated that the brain's ovulatory mechanism had been preserved together with a female pattern of sexual behavioural receptivity. Electron microscopy showed that structurally both these groups of rats had a female pattern of synapses in the preoptic area.

Conversely, neither the group of females treated with androgen on the fourth day of life nor the group of males castrated after the critical period was able to generate a preovulatory hormone surge as adults. Neither showed the female lordotic behavioural response to advances of male rats. Also, both had a male pattern of synapses in the preoptic area (Fig. 3).

Thus, the sexually dimorphic pattern of synapses in the preoptic area is determined not by the genetic sex of the rat but by the hormonal status during a critical perinatal period of development. This perinatal exposure correlates with the adult ability to generate a pre-ovulatory surge of hormones. The pattern of connections developing in the neonatal preoptic area showed plasticity with a binary outcome determined by the presence or absence of exposure to sex hormones (Raisman \& Field 1973). My publication appeared 2 years after Harris' death.

Published by Bioscientifica Ltd 


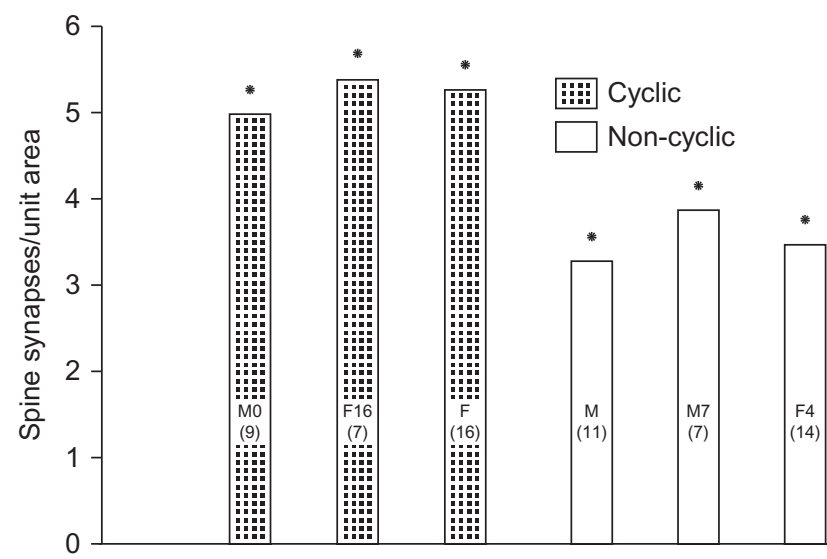

\section{Figure 3}

The mean incidences (dot=s.E.M.) of non-strial synapses per grid square from the preoptic area of each of the six groups of adult rats. $M$, intact males $(n=11)$, M0, males castrated at birth $(n=9)$, M7, males castrated on the 7th day of postnatal life $(n=7), \mathrm{F}$, intact females $(n=16)$. F4, females administered $1.25 \mathrm{mg}$ testosterone propionate on the fourth postnatal day $(n=14)$ and F16, females administered $1.25 \mathrm{mg}$ testosterone propionate on the 16th postnatal day $(n=7)$. The dotted bars indicate adult rats capable of an ovulatory surge of gonadotrophins. Reproduced from Brain Research, Raisman G \& Field PM, Sexual dimorphism in the neuropil of the preoptic area of the rat and its dependence on neonatal androgen, vol 54 pp 1-29, copyright 1973, with permission from Elsevier.

\section{Circadian rhythms: the suprachiasmatic syndrome}

With Keith I now set about trying to make an accurate determination of the location of the ovulatory trigger mechanism in the preoptic area. Our goal was to try to locate the smallest part of the preoptic area whose destruction would prevent ovulation in the normal adult female rat. The method was to make tiny areas of damage using a stereotaxically guided needle insulated to a tip that was heated by a controlled radiofrequency device.

We studied the location of the areas of damage and correlated them with the ability of adult female rats to ovulate. What we found was that the smallest lesion that would prevent ovulation was an area of damage that must include at least $75 \%$ of the suprachiasmatic nuclei on both sides (Brown-Grant \& Raisman 1977). This was a surprise. Neither was it the area where we had found sexual dimorphism, nor was it the area that Everett and others had identified as the generator of the pre-ovulatory surge of hormones.

Moreover, when these non-ovulating rats with the suprachiasmatic lesions were ovariectomised and tested with oestrogen priming followed by a single dose of progesterone, it was found that they were capable of generating a normal pre-ovulatory surge of pituitary gonadotrophic hormones. This was a puzzle. The brain's ovulatory mechanism was intact and yet the rats did not ovulate spontaneously. What was preventing them from ovulating?

The suprachiasmatic nuclei are named so because they are located immediately above the optic chiasma, and studies at that time had demonstrated that they receive a projection from the retina, a visual input (Hendrickson et al. 1972, Moore \& Lenn 1972). It was well known that the timing of ovulation in the rat depends on the lighting cycle. Every fourth or fifth afternoon, the pre-ovulatory surge of gonadotrophins began, and the rats become sexually receptive to the male that night. Could it be that the suprachiasmatic nuclei were the link between the light timing signal and the pre-ovulatory hormone surge? And that the link had been broken by the destruction of the nuclei?

Lesion studies in rats had demonstrated that lesions of the suprachiasma disrupt the circadian rhythms of drinking and locomotor activity (Stephan \& Zucker 1972) and corticosterone (Moore \& Eichler 1972). We decided to examine a number of rhythms in rats with lesions in and around the suprachiasmatic nuclei. The rat is a nocturnal animal, with its major activity during the hours of darkness. We used activity wheels to measure the periods of running activity, and with twice-daily weighing of the food and water bottles we could chart the periods of eating and drinking. We measured two plasma molecules with circadian rhythms - corticosterone, which peaks in the afternoon, and Les Iversen and Richard Zigmond measured pineal serotonin $\mathrm{N}$-acetyl transferase activity which peaks at night.

Confirming the results of earlier studies, all these rhythms were disorganised in the suprachiasmaticlesioned rats (Raisman \& Brown-Grant 1977). The failure of the ovulatory surge was due to disruption of the rat's circadian rhythm. And to prove that the brain's gonadotrophic control mechanisms were indeed intact, we showed that, after administration of progesterone, the rats would mate, ovulate, get pregnant, deliver and rear offspring normally.

\section{A mysterious photoreceptor}

Studying the light-darkness cycle of the rat led to another observation which, at the time, we could not explain. The rat ovulatory cycle depended on the cages being housed in a diurnal pattern of light-darkness cycles. If the rats were kept in constant light for 2 weeks, they stopped ovulating. These were albino rats whose eyes did not have the normal protective, energy-absorbing effect of pigment granules.

Published by Bioscientifica Ltd 
In collaboration with Mitch Glickstein, we examined the effect of 2 weeks of constant light on the histology of the albino rat retina. We found that the photoreceptor layer of the retina had disappeared. We could find no identifiable rods and cones remaining.

If the rats were now restored to normal light-darkness cycles, they resumed ovulating in normal 4 or 5 day cycles. But the retinal histology remained the same (Fig. 4). Something other than rods and cones was receiving the light signal (Glickstein et al. 1972).

The fact that rats without rods or cones could detect light was a puzzle. We could not have known at the time that there was a third photoreceptor, the melanopsin receptor expressed by cells in the retinal ganglion cell layer (Freedman et al. 1999, Lucas et al. 1999). For us, at the time, it remained a mystery.

\section{Regeneration of nerve fibres and an early view of apoptosis}

Another of Harris' discoveries also intrigued me. Much before this time, there had been a controversy between Geoffrey Harris and Solly, later Lord, Zuckerman. It was known that the ferret comes into heat in spring as the span of daylight lengthens. Harris saw this as an indication that a sensory input travelling through the eyes to the brain was converted eventually into hypothalamic humoral signals that would travel down his newly described pituitary portal vascular system to the pituitary gland to release gonadotrophins.

Zuckerman disliked Harris' theory and showed that, if he surgically transected the pituitary stalk in female ferrets, the animals still responded by coming into heat with increasing daylight (Zuckerman 1956). He described Harris' activity as 'an urge to explain the incomprehensible.' Even if we had had no explanation to this day, the word 'unknown' would have been perfectly acceptable. But the word 'incomprehensible' must go down as one of the most flagrant rejections of the very core of scientific method.

Harris simply repeated the experiment, but in addition to sectioning the pituitary stalk he placed a piece of greaseproof paper across the wound. Now the light response of the ferret was permanently blocked. Zuckerman's results were due to the fact that in the absence of a physical barrier, the portal vessels had regenerated across Zuckerman's wounds (for an account of this, see Raisman (1997). I was told that in his office at the Maudsley Hospital, Harris had mounted a framed photograph of Zuckerman's article in front of which he had suspended a pair of boxing gloves.

With my own interest in repair of severed nerve fibres, I was fascinated by the ability of the pituitary stalk to regenerate. The pituitary stalk contains not only blood vessels going from the median eminence to the anterior pituitary, but also the nerve fibres descending from the supraoptic and paraventricular nuclei to the posterior pituitary. These carry oxytocin and vasopressin via the
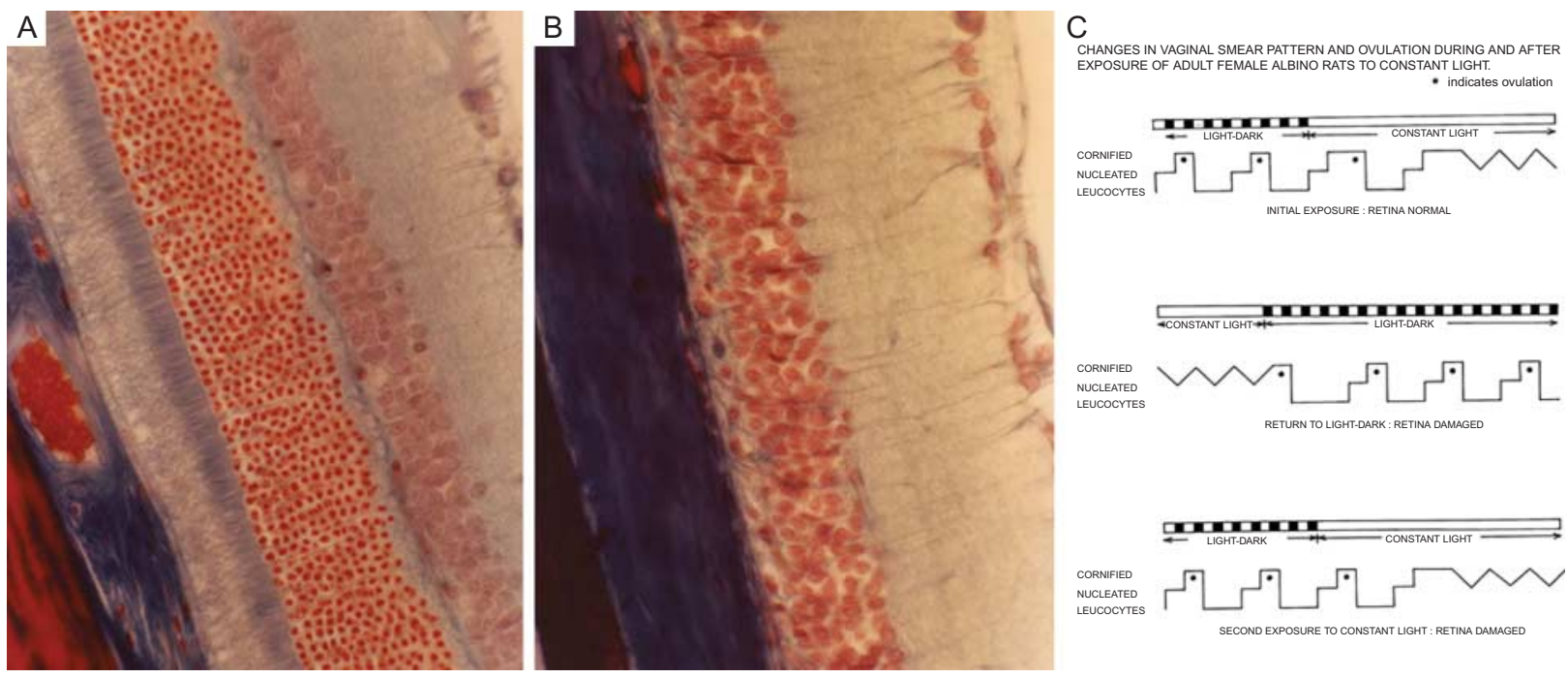

Figure 4

Cross-sections of the retina of Wistar albino rats $(A)$, caged with diurnal lighting, (B), after 2 weeks of constant light. Formalin fixation, haematoxylin and eosin stain. (C) chart of changes in the ovulatory cycle by vaginal smears. Reproduced, with permission, from Glickstein M, Brown-Grant K \&
Raisman G 1972 Light-induced retinal degeneration in the rat and its implications for endocrinological investigations. Journal of Anatomy 111 515. Copyright 1972 Anatomical Society.

Published by Bioscientifica Ltd 
pituitary into the general circulation, and are responsible for water balance and smooth muscle control in the reproductive system. It had already been shown that these fibres also regenerate (Adams et al. 1969).

I decided to examine the regeneration of this system in hypophysectomised rats. Over 1-4 months after hypophysectomy, a number of nerve fibres had indeed regenerated into a hypertrophic median eminence, which had become greatly enlarged by proliferation of its vasculature (Moll 1957, Raisman 1973a). Looking at the cell bodies of origin in the supraoptic nucleus over the first 9 days, the cells fell into two types (Raisman 1973b). Only approximately 15\% of the neurons were healthy, but engorged with secretory granules. Presumably, they were responding to the dehydration stimulus by increasing their individual output so as to contribute sufficient vasopressin to make up the entire renal need for water reabsorption.

We found similarly enlarged cells engorged with secretory granules in the supraoptic nuclei of the desert gerbil (G Raisman, unpublished observations). These are animals which do not drink water (obtaining it from their food) and which depend on maintaining a constitutively high level of vasopressin output to adapt to survival in arid environments.

What was interesting in our rats with pituitary stalk section was the situation of the remaining $85 \%$ of supraoptic neurons. They were shrunken, with dark cytoplasm, and their nuclei were dark, had lost their smooth ovoid outlines and were condensed into contorted shapes with patches of highly dense amorphous chromatin masses. These cells were entirely surrounded by phagocytic astroglia, and often appeared broken up into phagocytosed fragments within the glial cytoplasm. I believe that these may have been the first ultrastructural pictures of apoptosis (Kerr 1965). We speculated that these were cells whose axons had failed to regenerate to the new vasculature, as a result of which they had been deprived of the sustaining retrograde flow of sustaining growth factors present in the terminal region (Fig. 5).

\section{The Brattleboro rat mutant}

Before leaving the magnocellular hypothalamic nuclei, I had one more excursion. Interest in the control of water balance led me to look at the paraventricular and supraoptic neurons in the spontaneously occurring homozygous diabetes insipidus (di/di) Brattleboro strain of mutant rat. Brattleboro rats have a single-base deletion in the prohormone propressophysin gene required for synthesis of the nonapeptide vasopressin (antidiuretic hormone). They are

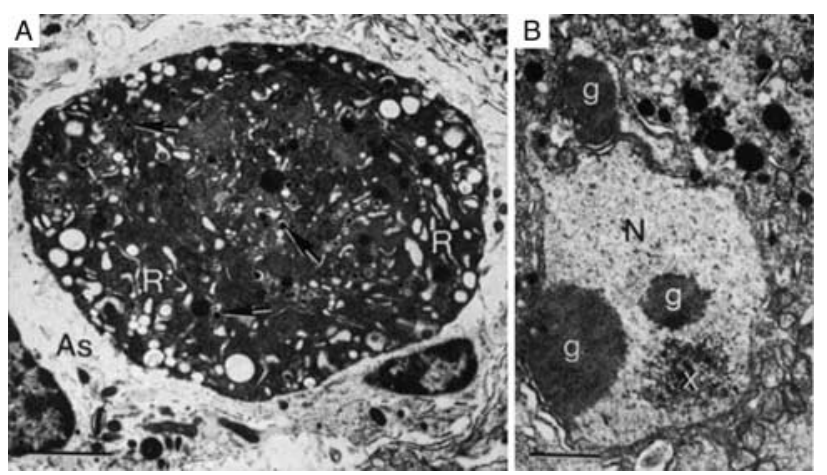

\section{Figure 5}

Evidence of apoptosis in degenerating supraoptic neurons after hypophysectomy. (A) A portion of highly electron-dense compacted cytoplasm from a degenerating supraoptic neuron at 4 days postoperative. $R$, endoplasmic reticulum, As, pale cytoplasm of a phagocytic astroglial process. (B). Nucleus (N) from a degenerating supraoptic neuron 9 days postoperative. g, masses of compacted granular chromatin material; x particulate deposit. Scale bars, $2 \mu \mathrm{m}$ in (A), $1.5 \mu \mathrm{m}$ in (B). Reproduced, with permission, from Raisman 1973b An ultrastructural study of the effects of hypophysectomy on the supraoptic nucleus of the rat. Journal of Comparative Neurology 147 181-208. Copyright 1973 The Wistar Institute Press.

polydipsic, produce ten times the normal urine volume and are under immense chronic dehydration stress.

The genetic defect occurs not in the coding region for the nonapeptide (exon A), but in exon B that codes for a neurophysin element necessary for the packaging of the peptide (Schmale \& Richter 1984). On counting all neurons through a continuous series of histological sections through the paraventricular nuclei of a series of eight Brattleboro rats (Richards et al. 1985), we found that approximately one in 600 of the magnocellular neurons was immunoreactive for vasopressin. However, the vasopressin was packaged abnormally in clumps rather than the usual dispersed pattern indicating cytoplasmic secretory granules. Subsequently, Evans et al. (2000) provided evidence that solitary magnocellular neurons of the di/di rat can regain the capacity to biosynthesise authentic vasopressin through +1 frameshifted precursors, but probably with impaired ER transit and sorting into the regulated secretory pathway (Fig. 6).

\section{A look into the future}

Harris died in 1971, at the early age of 58. In 1977, the Nobel Prize in Physiology or Medicine was divided, one half jointly to Roger Guillemin and Andrew V Schally 'for their discoveries concerning the peptide hormone production of the brain' (Wade 1981) and the other half to Rosalyn Yalow 'for the development of radioimmunoassays

Published by Bioscientifica Ltd 

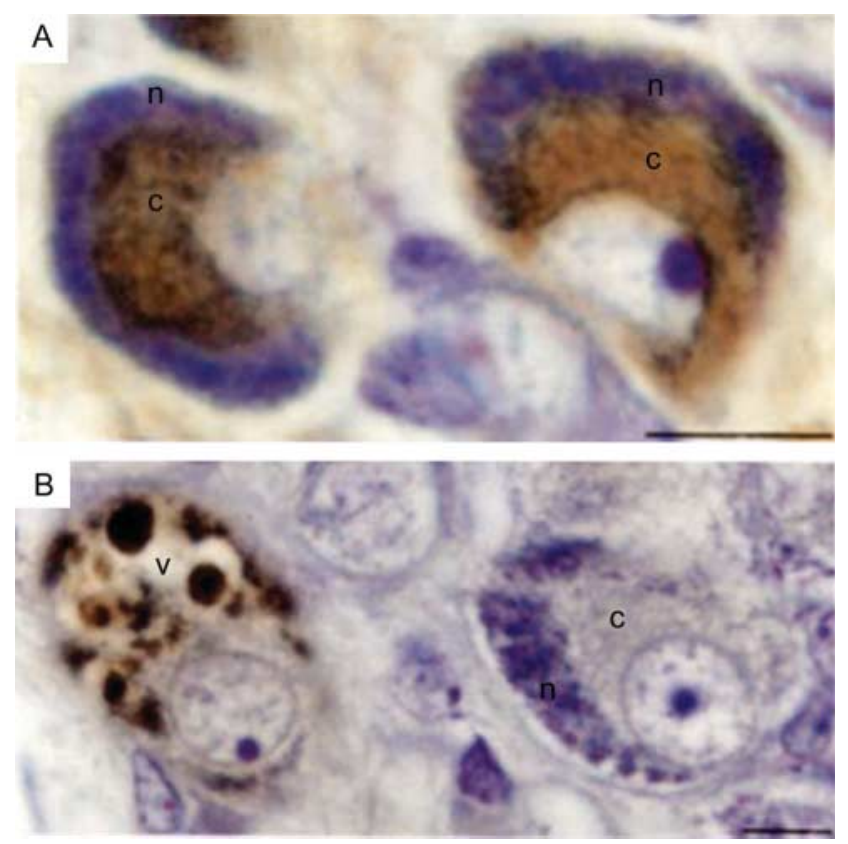

Figure 6

(A) Vasopressin (VP) immunoreactivity (brown) in paraventricular neurons of the WT Long-Evans strain rat. The normal distribution of the VP reaction product is in the cell centre (c), with the Nissl material ( $n$, blue) in the circumference of the cytoplasm. (B) VP expression in a single solitary neuron in the Brattleboro di/di mutant. The mutant VP $(v)$ is abnormally packaged as dense clumps throughout the cytoplasm. The adjacent neuron does not express VP. Scale bars, $20 \mu \mathrm{m}$. Reproduced from Neuroscience, Richards SJ, Morris RJ \& Raisman G, Solitary magnocellular neurons in the homozygous Brattleboro rat have vasopressin and glycopeptide immunoreactivity, vol 16 pp 617-623, Copyright 1985, with permission from Elsevier.

of peptide hormones'. These were Harris' 'releasing factors.' But this comment is no fitting epitaph.

For me, looking back on Harris' contribution, he seems as a titan, in direct line with the thinking laid down by Darwin, Claude Bernard and Francis Marshall, whose ideas formed the fundamental thread which ran through Harris' life's work. In a word - the mechanism of adaptation.

The value of scientific discoveries may be assessed not in terms of the questions solved, but in terms of those next questions that - as a result of those discoveries - can now be asked. What doors do the discoveries open? By such criteria, Harris was a towering giant, whose legacy is to leave us a vision of things wonderful and still unexplored.

With the master gone Harris' group melted away, Keith left Oxford and the subject of neuroendocrinology, which Harris had done so much to establish, entered a new phase. For me, it was the end of a brief and glowing interlude in my scientific life, between the discovery of plasticity in the septal nuclei, and my later work on the problem of repairing axon injuries in the spinal cord (Li et al. 1997, Tabakow et al. 2014). But I left the neuroendocrine world with a strong sense of unfinished business. This arose from observations by others at the time, and if I could have imagined a practical way of investigating them I would have been really tempted. They are two mysteries that intrigue me still. They both refer to something I would call the endocrine memory of the brain.

\section{How does the rat remember it has mated?}

The first relates to the induction of pseudopregnancy (Harris 1936). After mating, the rat goes into a period of high prolactin and progesterone production, which suppresses further ovulation and prepares the corpus luteum and the uterus for implantation. However, if the mating is sterile (e.g. as a result of the placing of an obstruction on the vaginal opening), the rat simply goes into the next ovulation in 4 or 5 days. Provided it is not then mated, this second ovulation is followed by a period of suppression of ovulation, called a pseudopregnancy (Keith Brown-Grant personal communication; (Jacobson et al. 1950)). Something in the brain has remembered that the rat has already mated.

My question was where is this memory located? Is it simply due to a post-copulatory change in the levels of neurosecretory hormones (e.g. a depletion of vasopressin in the supraoptic and paraventricular nuclei)? Is it a longterm electrophysiological event? Is it a change in synaptology, such as has been shown to occur in the hypothalamic arcuate nucleus during the oestrous cycle (Naftolin et al. 1990, 1996)? Those are still unsolved questions I would love to have investigated.

\section{What are ovulons?}

The second instance of endocrine memory relates to the dose of steroids, which given to a neonatal female rat will prevent all ovulation for life. If this dose is reduced, the rat goes through puberty and carries out a small number of ovulations, the number being inversely related to the dose of steroid given (Arai \& Matsumoto 1978, Arai et al. 1996). Clearly, the effect of the partial steroid doses leaves part of the ovulatory mechanism of the brain intact. In Keith Brown-Grant's words, it is as though the brain has a certain number of 'ovulons.' But where are they and how could they be measured?

With these two reluctant over-the-shoulder looks, I left the field of neuroendocrinology.

But still for me, 40 years later, the control of the endocrine system and of reproduction remains as one of the most fascinating aspects and vital functions of the

Published by Bioscientifica Ltd 
brain. Who knows what treasures await discovery in that Aladdin's cave?

\section{Chronobiology}

Marshall's and Harris' work had centred on cyclic events and, above all, on critical periods and timing. In his first lecture in Oxford, Keith Brown-Grant pointed out the factor of timing in the endocrine system. The adrenal cortex responds to stress in seconds - the thyroid gland responds to temperature changes in months. The timing is in terms of days for the rat oestrous cycle. It is in terms of months for the onset of puberty in rats. It is in terms of years for human menarche and menopause.

But where do these time givers lie? Memory depends on timing - the time to establish a memory, the time for it to remain active, the time for it to be forgotten and, if the function is to be cyclic, the time for it to be re-born. All these functions are under control of the brain - engrams. These engrams underlie endocrine cyclicity. But survival depends on the body's endocrine cycles interacting adaptively with the external cycles of climate and season, and the availability of mates and food. The brain's engrams must lock into the phase of the environment's cycles. We are only at a very early stage in understanding as to how the brain achieves these vital functions (e.g. the thyroid-pars tuberalis axis (Yoshimura 2013)).

Electrophysiology has traditionally described the function of the nervous system in terms of millisecond events and action potentials travelling down axons with the speed of cars on a road. The discovery of long-term potentiation (Bliss \& Lomo 1973) was one of the first indications of the importance of CNS events lasting for $24 \mathrm{~h}$. With the growing recognition of the discipline of 'chronobiology' (Foster \& Kreitzman 2014), we are starting to come to grips with the question of how the nervous system measures and deals with long-term events.

As Harris' work so clearly demonstrates, reproduction depends on cyclic events in the brain. Reproduction is, after all, and for all living things, the final common path of evolution, the most crucial to survival of the species and the most highly conserved of all functions. For all the current interest in imaging the cognitive processes of the brain, it is still one of the least studied functions of the nervous system. The brain's control of reproduction is the lonely Cinderella still waiting for her Prince Charming to fit the glass slipper.

\section{Declaration of interest}

The author declares that there is no conflict of interest that could be perceived as prejudicing the impartiality of this review.

\section{Funding}

The author is supported by the UK Stem Cell Foundation and the Nicholls Spinal Injury Foundation.

\section{Acknowledgements}

I am grateful to Russell Foster and Brian Follett who helped me fill in some of the worst gaps in my poor knowledge of neuroendocrinology, and corrected my fading memories of those days, and especially to the survivors from those heroic times, Seymour (Si) Reichlin and Fred Naftolin, possibly Harris' first and last students.

\section{References}

Adams JH, Daniel PM \& Prichard MM 1969 Degeneration and regeneration of hypothalamic nerve fibers in the neurohypophysis after pituitary stalk section in the ferret. Journal of Comparative Neurology 135 121-144. (doi:10.1002/cne.901350202)

Arai Y \& Matsumoto A 1978 Synapse formation of the hypothalamic arcuate nucleus during post-natal development in the female rat and its modification by neonatal estrogen treatment. Psychoneuroendocrinology 3 31-45. (doi:10.1016/0306-4530(78)90039-2)

Arai Y, Sekine Y \& Murakami S 1996 Estrogen and apoptosis in the developing sexually dimorphic preoptic area in female rats. Neuroscience Research 25 403-407. (doi:10.1016/0168-0102(96)01070-X)

Bargmann W 1966 Neurosecretion. International Review of Cytology 19 183-201. (doi:10.1016/S0074-7696(08)60567-7)

Bliss TV \& Lomo T 1973 Long-lasting potentiation of synaptic transmission in the dentate area of the anaesthetized rabbit following stimulation of the perforant path. Journal of Physiology 232 331-356. (doi:10.1113/ jphysiol.1973.sp010273)

Brown-Grant K \& Raisman G 1977 Abnormalities in reproductive function associated with the destruction of the suprachiasmatic nuclei in female rats. Proceedings of the Royal Society of London 198 279-296. (doi:10.1098/rspb.1977.0098)

Cajal SR 1911 In Histologie du système nerveux de l'homme et des vertébrés. Paris, France: Maloine A. (available at: https://archive.org/details/ histologiedusyst01ram)

Clarkson J, Busby ER, Kirilov M, Schutz G, Sherwood NM \& Herbison AE 2014 Sexual differentiation of the brain requires perinatal kisspeptinGnRH neuron signaling. Journal of Neuroscience 34 15297-15305. (doi:10.1523/JNEUROSCI.3061-14.2014)

Douglas WW \& Poisner AM 1964 Stimulus-secretion coupling in a neurosecretory organ: the role of calcium in the release of vasopressin from the neurohypophysis. Journal of Physiology 172 1-18. (doi:10.1113/jphysiol.1964.sp007399)

Evans DA, De Bree FM, Nijenhuis M, Van Der Kleij AA, Zalm R, Korteweg N, Van Leeuwen FW \& Burbach JP 2000 Processing of frameshifted vasopressin precursors. Journal of Neuroendocrinology 12 685-693. (doi:10.1046/j.1365-2826.2000.00507.x)

Everett JW \& Sawyer CH 1950 A 24-hour periodicity in the "LH-release apparatus" of female rats, disclosed by barbiturate sedation. Endocrinology 47 198-218. (doi:10.1210/endo-47-3-198)

Everett JW, Sawyer CH \& Markee JE 1949 A neurogenic timing factor in control of the ovulatory discharge of luteinizing hormone in the cyclic rat. Endocrinology 44 234-250. (doi:10.1210/endo-44-3-234)

Foster RG \& Kreitzman L 2014 The rhythms of life: what your body clock means to you! Experimental Physiology 99 599-606. (doi:10.1113/ expphysiol.2012.071118)

Freedman MS, Lucas RJ, Soni B, von Schantz M, Munoz M, David-Gray Z \& Foster R 1999 Regulation of mammalian circadian behavior by non-rod, non-cone, ocular photoreceptors. Science 284 502-504. (doi:10.1126/ science.284.5413.502)

Published by Bioscientifica Ltd 
Glickstein M, Brown-Grant K \& Raisman G 1972 Light-induced retinal degeneration in the rat and its implications for endocrinological investigations. Journal of Anatomy 111515.

Harris GW 1936 The induction of pseudopregnancy in the rat by electrical stimulation through the head. Journal of Physiology 88 361-367. (doi:10.1113/jphysiol.1936.sp003446)

Harris GW 1937 The induction of ovulation in the rabbit, by electrical stimulation of the hypothalamo-hypophysial mechanism. Proceedings of the Royal Society of London 122 374-394. (doi:10.1098/rspb.1937. 0031)

Harris GW 1972 Humours and hormones. The Sir Henry Dale Lecture for 1971. Journal of Endocrinology 53 1-23. (doi:10.1677/joe.0.0530001)

Harris GW \& Campbell HJ. 1966 The regulation of the secretion of luteinizing hormone and ovulation. In The Pituitary Gland, vol 2, pp 99-165. Eds GW Harris \& HJ Campbell. London: Butterworths.

Hendrickson AE, Wagoner N \& Cowan WM 1972 An autoradiographic and electron microscopic study of retino-hypothalamic connections.

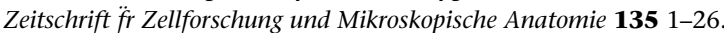
(doi:10.1007/BF00307084)

Hubble D 1961 The endocrine orchestra. BMJ 1 523-528. (doi:10.1136/bmj. 1.5225.523)

Jacobson A, Salhanick HA \& Zarrow MX 1950 Induction of pseudopregnancy and its inhibition by various drugs. American Journal of Physiology $161522-527$.

Kerr JF 1965 A histochemical study of hypertrophy and ischaemic injury of rat liver with special reference to changes in lysosomes. Journal of Pathology and Bacteriology 90 419-435. (doi:10.1002/path.1700900210)

Koves K \& Halasz B 1970 Location of the neural structures triggering ovulation in the rat. Neuroendocrinology 6 180-193. (doi:10.1159/ 000121922)

Li Y, Field PM \& Raisman G 1997 Repair of adult rat corticospinal tract by transplants of olfactory ensheathing cells. Science 277 2000-2002. (doi:10.1126/science.277.5334.2000)

Lucas RJ, Freedman MS, Munoz M, Garcia-Fernandez JM \& Foster RG 1999 Regulation of the mammalian pineal by non-rod, non-cone, ocular photoreceptors. Science 284 505-507. (doi:10.1126/science.284.5413.505)

Marshall FH. 1922 The Phyiology of Reproduction, 2nd edn. London: Longmans, Green \& Co.

Moll J 1957 Regeneration of the supraoptico-hypophyseal and paraventriculo-hypophyseal tracts in the hypophysectomized rat. Zeitschrift $\ddot{f r}$ Zellforschung und Mikroskopische Anatomie 46 686-709. (doi:10.1007/ BF00339372)

Money J \& Ehrhardt AA 1971 Fetal hormones and the brain: effect on sexual dimorphism of behavior - a review. Archives of Sexual Behavior 1 241-262. (doi:10.1007/BF01541686)

Money J, Ehrhardt AA \& Masica DN 1968 Fetal feminization induced by androgen insensitivity in the testicular feminizing syndrome: effect on marriage and maternalism. Johns Hopkins Medical Journal 123 105-114.

Moore RY \& Eichler VB 1972 Loss of a circadian adrenal corticosterone rhythm following suprachiasmatic lesions in the rat. Brain Research 42 201-206. (doi:10.1016/0006-8993(72)90054-6)

Moore RY \& Lenn NJ 1972 A retinohypothalamic projection in the rat. Journal of Comparative Neurology 146 1-14. (doi:10.1002/cne. 901460102)

Naftolin F, Garcia-Segura LM, Keefe D, Leranth C, Maclusky NJ \& Brawer JR 1990 Estrogen effects on the synaptology and neural membranes of the rat hypothalamic arcuate nucleus. Biology of Reproduction 42 21-28. (doi:10.1095/biolreprod42.1.21)

Naftolin F, Leranth C, Horvath TL \& Garcia-Segura LM 1996 Potential neuronal mechanisms of estrogen actions in synaptogenesis and synaptic plasticity. Cellular and Molecular Neurobiology 16 213-223. (doi:10.1007/BF02088177)
Pfeiffer CA 1936 Sexual differences of the hypophyses and their determination by the gonads. American Journal of Anatomy 58 195-225. (doi:10.1002/aja.1000580112)

Raisman G $1969 a$ Neuronal plasticity in the septal nuclei of the adult rat. Brain Research 14 25-48. (doi:10.1016/0006-8993(69)90029-8)

Raisman G $1969 b$ A comparison of the mode of termination of the hippocampal and hypothalamic afferents to the septal nuclei as revealed by electron microscopy of degeneration. Experimental Brain Research 7 317-343. (doi:10.1007/BF00237319)

Raisman G 1973a Electron microscopic studies of the development of new neurohaemal contacts in the median eminence of the rat after hypophysectomy. Brain Research 55 245-261. (doi:10.1016/00068993(73)90294-1)

Raisman G 1973b An ultrastructural study of the effects of hypophysectomy on the supraoptic nucleus of the rat. Journal of Comparative Neurology 147 181-208. (doi:10.1002/cne.901470204)

Raisman G 1978 La différence de structure entre les cerveaux male et femelle chez le rat. In Le Fait Feminin, pp 93-98. Eds E Sullérot \& O Thibault. Paris: Fayard.

Raisman G 1997 An urge to explain the incomprehensible: Geoffrey Harris and the discovery of the neural control of the pituitary gland. Annual Review of Neuroscience 20 533-566. (doi:10.1146/annurev.neuro.20.1.533)

Raisman G \& Brown-Grant K 1977 The 'suprachiasmatic syndrome': endocrine and behavioural abnormalities following lesions of the suprachiasmatic nuclei in the female rat. Proceedings of the Royal Society of London 198 297-314. (doi:10.1098/rspb.1977.0099)

Raisman G \& Field PM 1971 Sexual dimorphism in the preoptic area of the rat. Science 173 731-733. (doi:10.1126/science.173.3998.731)

Raisman G \& Field PM 1973 Sexual dimorphism in the neuropil of the preoptic area of the rat and its dependence on neonatal androgen. Brain Research 54 1-29. (doi:10.1016/0006-8993(73)90030-9)

Richards SJ, Morris RJ \& Raisman G 1985 Solitary magnocellular neurons in the homozygous Brattleboro rat have vasopressin and glycopeptide immunoreactivity. Neuroscience 16 617-623. (doi:10.1016/0306-4522 (85)90196-4)

Scharrer B 1936 Über "Drüsen-Nervenzellen" im Gehirn von Nereis virens Sars. Zoologischer Anzeiger 113 299-302.

Schmale H \& Richter D 1984 Single base deletion in the vasopressin gene is the cause of diabetes insipidus in Brattleboro rats. Nature 308 705-709. (doi:10.1038/308705a0)

Stephan FK \& Zucker I 1972 Circadian rhythms in drinking behavior and locomotor activity of rats are eliminated by hypothalamic lesions. PNAS 69 1583-1586. (doi:10.1073/pnas.69.6.1583)

Tabakow P, Raisman G, Fortuna W, Czyz M, Huber J, Li D, Szewczyk P, Okurowski S, Miedzybrodzki R, Czapiga B et al. 2014 Functional regeneration of supraspinal connections in a patient with transected spinal cord following transplantation of bulbar olfactory ensheathing cells with peripheral nerve bridging. Cell Transplantation 23 1631-1655. (doi:10.3727/096368914X685131)

Velasco ME \& Taleisnik S 1969 Release of gonadotropins induced by amygdaloid stimulation in the rat. Endocrinology 84 132-139. (doi:10.1210/endo-84-1-132)

Vogt ML 1972 Geoffrey Wingfield Harris, 1913-1971. Biographical Memoirs of Fellows of the Royal Society 18 309-329. (doi:10.1098/rsbm.1972.0010)

Wade N 1981 The Nobel Duel. New York: Anchor Press.

Yoshimura T 2013 Thyroid hormone and seasonal regulation of reproduction. Frontiers in Neuroendocrinology 34 157-166. (doi:10.1016/ j.yfrne.2013.04.002)

Zuckerman S 1956 Control of pituitary function. Nature 178 442-443. (doi:10.1038/178442a0)

Received in final form 30 January 2015

Accepted 10 February 2015

Accepted Preprint published online 10 February 2015

Published by Bioscientifica Ltd http://joe.endocrinology-journals.org

DOI: 10.1530/JOE-15-0049
(C) 2015 Society for Endocrinology Printed in Great Britain 